\title{
Mastoid osteoma: A rare incidental finding in an orthodontic patient
}

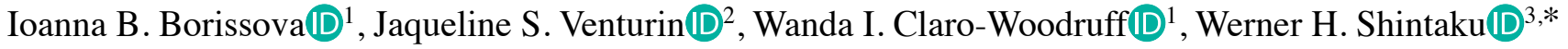 \\ ${ }^{1}$ Department of Orthodontics, University of Tennessee Health Sciences College of Dentistry, Memphis, TN, USA \\ ${ }^{2}$ Department of Diagnostic Sciences, Division of Oral Diagnosis, University of Tennessee Health Sciences College of Dentistry, Memphis, TN, USA \\ ${ }^{3}$ Department of Diagnostic Sciences, Division of Oral and Maxillofacial Radiology, University of Tennessee Health Sciences College of Dentistry, \\ Memphis, TN, USA
}

\section{ABSTRACT}

\begin{abstract}
Mastoid osteomas of the temporal bone are rare, benign, and usually asymptomatic tumors. However, depending on their size and extension, mastoid osteomas may cause facial palsy, a sensation of ear fullness, pressure-related pain, hearing loss, recurrent external ear infections, and chronic discharge. The etiology of mastoid osteomas is still unknown, but congenital, infectious, and traumatic factors have been proposed. Surgical treatment may be performed with minimal postoperative morbidity. In this article, the authors report a case of a 48 -year-old woman seeking orthodontic treatment with an unusual retroauricular protruding mass, including the diagnostic process and differential diagnosis. This case supports the essential role of cone-beam computed tomography to analyze and identify the lesion as a mastoid osteoma. (Imaging Sci Dent 2020; 50: 347-51)
\end{abstract}

KEY WORDS: Osteoma; Cone-Beam Computed Tomography; Orthodontics; Head

Osteomas are benign, slowly growing, osteoblastic mesenchymal tumors that may be classified based on their location, size, and extension. ${ }^{1}$ In the head and neck, osteomas are found mostly in the frontal and ethmoid sinuses. Temporal osteomas are rare and most frequently involve the external auditory canal, which may cause occlusion of the external meatus and deafness. ${ }^{2}$ Nonetheless, osteomas may occur in all portions of the temporal bone, including the squamous part, mastoid part, internal auditory canal, glenoid fossa, middle ear, Eustachian tube, petrous apex, and styloid process. ${ }^{3}$ Mastoid osteomas are rare tumors composed of well-differentiated osseous tissue in a laminar and circumscribed arrangement arising from the cortex of the mastoid body and growing outward from the external surface of the mastoid process. ${ }^{1-6}$

Most mastoid osteomas are asymptomatic, but they may cause pain due to invasion of the cranial vault or esthetic

Received June 25, 2020; Revised July 22, 2020; Accepted August 14, 2020 *Correspondence to : Dr. Werner H. Shintaku

Department of Diagnostic Sciences, Division of Oral and Maxillofacial Radiology, University of Tennessee Health Sciences College of Dentistry, 875 Union Avenue, Memphis, TN 38163, USA

Tel)1-901-448-2845,E-mail)wshintak@uthsc.edu deformities by displacing the auricle forward. ${ }^{3}$ Usually, mastoid osteomas are less than $10 \mathrm{~mm}$ in diameter, but tumors larger than $30 \mathrm{~mm}$, known as giant osteomas, have been reported. ${ }^{7-9}$

The clinical characteristics of size and location are essential for the diagnosis of mastoid osteomas. Radiographic 3-dimensional (3D) images provide valuable information about density, contours, size, and the extension of the lesion to support the diagnosis of mastoid osteoma. ${ }^{10}$ In this case report, the diagnosis of a rare mastoid osteoma in a patient seeking orthodontic treatment was described.

\section{Case Report}

A 48-year-old African-American woman presented to the postgraduate orthodontic clinic of the University of Tennessee College of Dentistry seeking orthodontic treatment. This case report was approved by the Institutional Review Board (Protocol: 20-07274-NHSR), and the collected data were only accessible to the authors.

During the initial clinical appointment, a hard swelling in the left postauricular region was noted (Fig. 1). Clinically, 
the swelling measured about $27 \mathrm{~mm} \times 28 \mathrm{~mm}$. The local skin had a healthy appearance and average temperature. The patient had noticed the swelling about 10 years ago when the frame of her glasses started to put pressure on it. She stated that she had not experienced any symptoms, such as pain or dizziness. The patient was in good health and reported no history of local trauma, chronic inflammation, cranial nerve alterations, or hearing changes. The facial nerve was intact.

A radiographic exam using cone-beam computed tomography (CBCT) was acquired to assess the lesion and for orthodontic purposes. The tomographic images were obtained with a ProMax 3D scanner (Planmeca, Helsinki, Finland) using settings of $90 \mathrm{kV}, 10 \mathrm{~mA}$, and 14 seconds of exposure time. The exposure settings were automatically

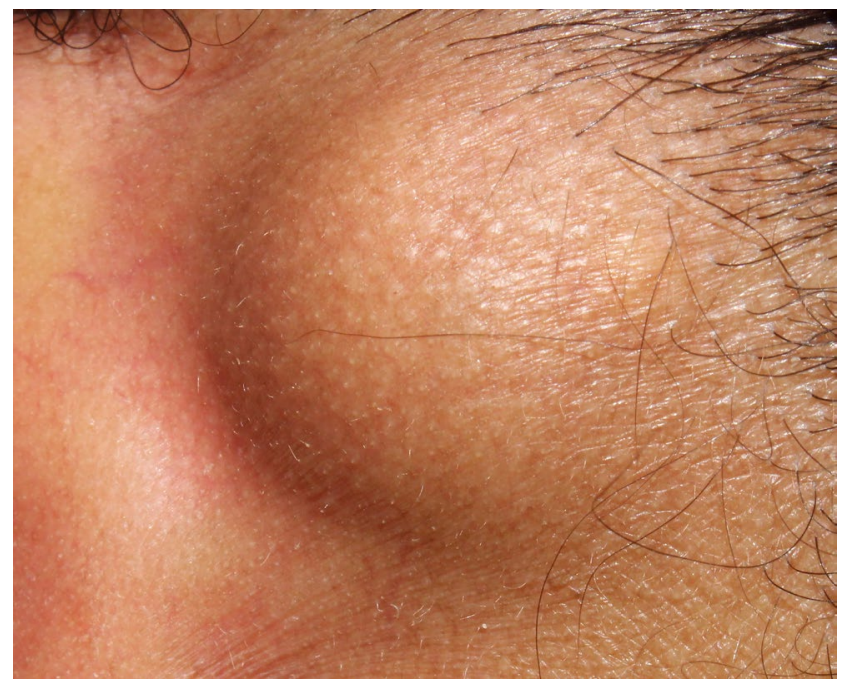

Fig. 1. Clinical photograph shows a left postauricular swelling. optimized for the patient's size. The dimensions of the volume were $230 \mathrm{~mm} \times 160 \mathrm{~mm}$ with a voxel size of $0.4 \mathrm{~mm}^{3}$. The images were evaluated by a board-certified oral and maxillofacial radiologist using OnDemand 3D (Cybermed Inc., Seoul, Korea) in a dimly lit room on a 27 inch Dell U2715 monitor (Dell Inc., Round Rock, TX, USA).

The CBCT images showed a well-defined exophytic outgrowth attached to the retromastoid portion of the left temporal bone (Fig. 2). The lesion measured $14 \mathrm{~mm} \times 15$ $\mathrm{mm} \times 19 \mathrm{~mm}$ and was sessile in the superior and anterior portions. The inferior and posterior parts were pedunculated. Most of the lesion showed density similar to cortical bone with localized superficial areas of lower density (Fig. 3). The outgrowth involved only the mastoid bone without osteolytic lesions or invasion of the cranial vault. Exostoses into the left auditory canal were not observed. The left mastoid air cells were clear and intact. The diagnosis of benign compact mastoid osteoma was determined based on clinical and radiographic findings. The patient was notified of the diagnosis and opted not to pursue treatment. No noticeable clinical changes were observed at a 6-month follow-up appointment.

\section{Discussion}

Osteomas usually occur in long bones like the femur's proximal shaft $(19 \%)$ or proximal tibia $(10 \%){ }^{5}$ In the head and neck, craniofacial osteomas are the most common primary benign tumor of the skull and facial bones. These osteomas are most commonly found in the frontal and ethmoid sinuses, but may occur in the external auditory canal, glenoid fossa, and styloid process. ${ }^{3,6,11,12}$ In the general

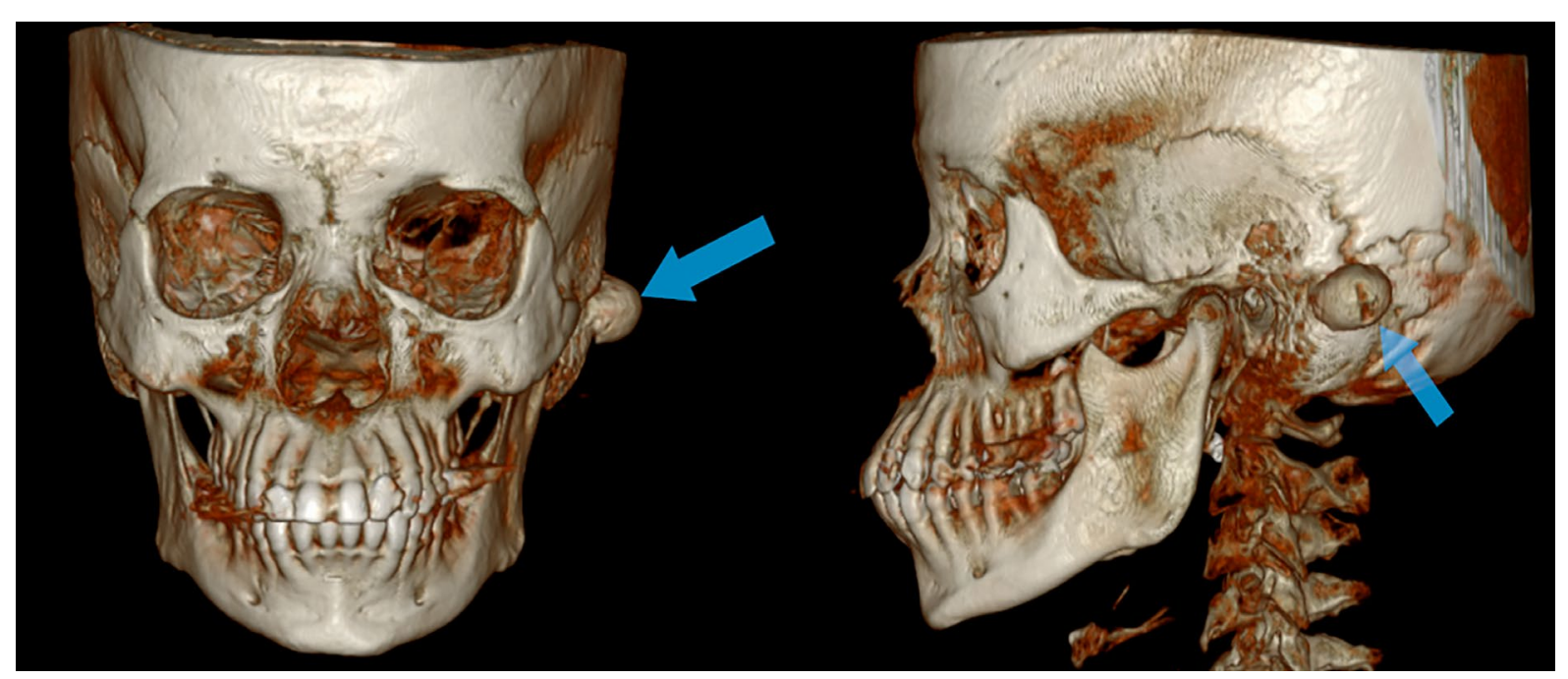

Fig. 2. Three-dimensional reconstructions in coronal (left) and lateral (right) views show the mastoid osteoma on the left temporal bone. 


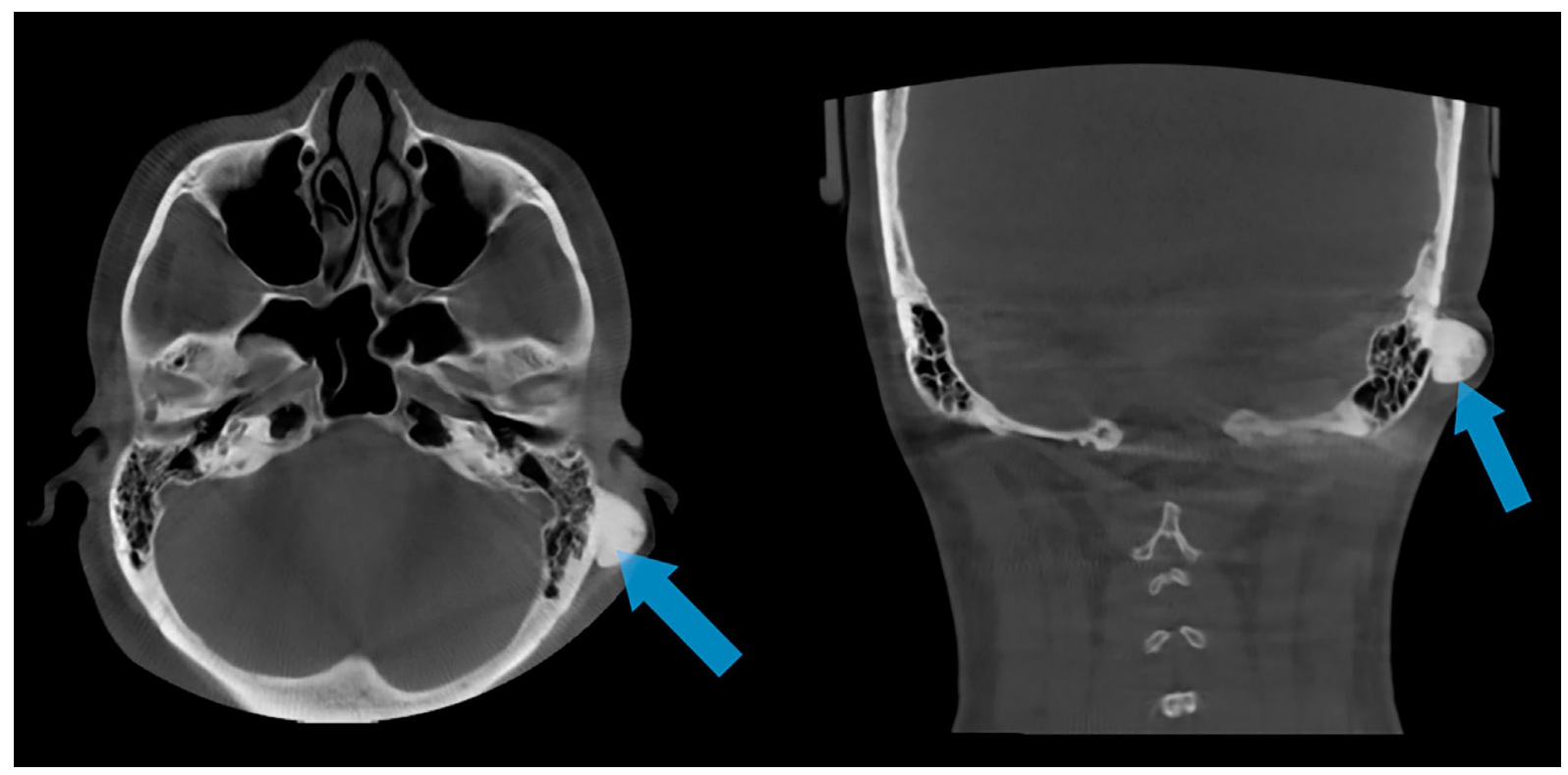

Fig. 3. Axial (left) and coronal (right) computed tomographic images show the mastoid osteoma on the left temporal bone.

population, craniofacial osteomas account for $0.43 \%$ of tumors, and as well as $1 \%$ of incidental findings on plain radiographs and $3 \%$ of incidental findings on $\mathrm{CT}$ exams. ${ }^{8,13}$ Maxillofacial osteomas are classified as peripheral osteomas and most commonly arise in the mandible, followed by the maxilla, temporal bone, and maxillary sinus. ${ }^{14}$ Mastoid osteomas are temporal osteomas attached to the cortex of the mastoid bone and are very rare, representing about $0.1 \%$ to $1 \%$ of all benign tumors of the skull. ${ }^{1,3,5,6,15-17}$ Mastoid osteomas have a higher incidence in females, predominantly in the second and third decades of life. ${ }^{3,18}$ Our patient supports these tendencies.

The etiology of mastoid osteoma is still unknown, but the accepted theories of mastoid osteoma include congenital, infectious, and traumatic origins. ${ }^{1,12,19,20}$ In our case, a congenital origin was deemed to be most likely because the patient reported no previous infection or trauma.

Typically, an osteoma is a solitary lesion. ${ }^{21}$ In the presence of numerous osteomas, Gardner syndrome must be ruled out. ${ }^{5}$ Since osteomas precede the clinical and radiographic evidence of colonic polyposis, they may help in the diagnosis of Gardner syndrome. ${ }^{22}$ Gardner syndrome is an autosomal dominant hereditary disease associated with multiple osteomas, subcutaneous fibromas and lipomas, desmoid tumors, epidermal cysts and, most importantly, intestinal polyposis. ${ }^{3,5,10}$ These intestinal polyps have a high risk of malignant transformation and must be followed-up carefully. Our patient showed a single osteoma without additional findings supportive of Gardner syndrome.
Craniofacial osteomas are usually asymptomatic and are considered as an incidental finding. ${ }^{23}$ However, mastoid osteoma may present signs and symptoms such as facial palsy, the sensation of ear fullness, pressure-related pain, hearing loss due to meatal obstruction, and chronic discharge. ${ }^{1,3,21}$ In a case report, Van Dellen ${ }^{24}$ described a mastoid osteoma causing intracranial complications due to displacement and compression of structures in the posterior cranial fossa. Another report described a trauma-related mastoid osteoma in a 19-year-old woman with recurrent postauricular pain. ${ }^{19}$ In our case, the lesion was utterly asymptomatic, as the patient reported no signs or symptoms other than pressure in the region when wearing glasses.

Histologically, mastoid osteomas have 2 variants depending on the proportions of dense and cancellous bone. ${ }^{1,6,17,21,25}$ Compact or ivory osteomas are more common and have a normal-appearing lamellar bone with minimal marrow tissue and an occasional Haversian system. Spongy or cancellous osteomas are rare and contain trabeculae of mature lamellar bone with fatty fibrous marrow and osteoblasts. $^{22}$

$\mathrm{CT}$ is the imaging method of choice to evaluate mastoid osteomas and is useful to differentiate it from other mastoid osseous tumors of the temporal bone..$^{3,10,17,21}$ Radiographically, mastoid osteomas appear as a well-circumscribed osseous outgrowth attached to the outer cortex of the mastoid bone and may be pedunculated or sessile. Compact osteomas appear as a homogenous sclerotic overgrowth with a density similar to healthy cortical bone, have a sessile base, 
and show prolonged slow growth. Spongy osteomas exhibit a central low dense area (comparable to bone marrow) surrounded by sclerotic bone, a pedunculated base, and somewhat faster growth than compact osteomas. ${ }^{17,21}$

In our case, the clinical findings of an asymptomatic, slowly growing lesion and radiographic features of a well-delimited cortical bone-like outgrowth with typical osseous architecture determined the diagnosis of mastoid osteoma.

The differential diagnosis of mastoid osteomas includes exostoses, periosteal osteoblastoma, and osteosarcoma. ${ }^{3,21,26}$ Exostoses are typically multiple and broad-based growths that stop progressing after puberty. In contrast, osteomas are mostly single and pedunculated, and may continue to grow after puberty. ${ }^{3,22}$ Periosteal osteoblastomas show heterogeneous density with more prominent areas of lower bone density, are painful, and exhibit rapid growth. ${ }^{22}$ As a malignant lesion, osteosarcoma has poorly defined margins and an osteolytic appearance, causes pain, and grows quite rapidly. ${ }^{10}$ None of these features were present in our case.

Asymptomatic mastoid osteomas do not require prompt intervention. ${ }^{7}$ En bloc surgical resection with a retroauricular approach under general anesthesia is indicated in symptomatic osteomas or for cosmetic reasons. The mastoid plate must be drilled until the unaffected cortical tissue is reached to prevent recurrence. Craniotomy and cranioplasty may be considered for giant tumors. ${ }^{1}$ Cortical mastoidectomy should be performed if the mastoid air cells are exposed. ${ }^{27}$ Recurrence after surgical removal is rare, and there are no reported cases of malignant transformation. 3,28 In our case, since the mastoid osteoma was asymptomatic and there were no esthetic concerns, the patient decided not to pursue surgical removal and will be followed-up for any changes.

This report emphasizes the thorough evaluation of patients beyond the stomatognathic system and supports the use of radiographic exams to assess a lesion thoroughly. Mastoid osteomas are slowly growing benign tumors attached to the outer cortex of the temporal bone and are very rare. Still, in the presence of a firm mass in the retroauricular region, mastoid osteoma should be considered as a possible diagnosis. CT is the imaging method of choice to assess the lesion and obtain relevant information for diagnosis and treatment. Surgical removal is indicated in the presence of symptoms, such as hearing loss and pain, or for cosmetic reasons. The treatment prognosis of mastoid osteoma is very good, as recurrence is rare and malignant transformation has never been reported.

\section{Conflicts of Interest: None}

\section{References}

1. Tan EW, Barco JB, Rehman MU, Tan CC. Retromastoid osteoma - a rare case report. J Surg Case Rep 2020; 2020: rjz381.

2. Schwartz LJ. Osteoma of the mastoid. Arch Otolaryngol 1961; 74: 350-3.

3. Kandakure VT, Lahane VJ, Mishra S. Osteoma of mastoid bone; a rare presentation: case report. Indian J Otolaryngol Head Neck Surg 2019; 71(Suppl 2): 1030-2.

4. Karatas A, Cebi IT, Yanik T, Kocak A, Selcuk T. Osteoma originating from mastoid cortex. Turk Arch Otorhinolaryngol 2017; 55: 48-50.

5. Smud D, Augustin G, Kekez T, Kinda E, Majerovic M, Jelincic Z. Gardner's syndrome: genetic testing and colonoscopy are indicated in adolescents and young adults with cranial osteomas: a case report. World J Gastroenterol 2007; 13: 3900-3.

6. Dhingra R, Davessar JL, Midha N, Singh H, Monga S. Osteoma: a rare case of painless postauricular swelling. Indian J Otolaryngol Head Neck Surg 2019; 71(Suppl 2): 1238.

7. Haddad FS, Haddad GF, Zaatari G. Cranial osteomas: their classification and management. Report on a giant osteoma and review of the literature. Surg Neurol 1997; 48: 143-7.

8. Yudoyono F, Sidabutar R, Dahlan RH, Gill AS, Ompusunggu SE, Arifin MZ. Surgical management of giant skull osteomas. Asian J Neurosurg 2017; 12: 408-11.

9. Erten F, Hasturk AE, Pak I, Sokmen O. Giant occipital osteoid osteoma mimicking calcified meningioma. Neurosciences (Riyadh) 2011; 16: 363-5.

10. El Fakiri M, El Bakkouri W, Halimi C, Ait Mansour A, Ayache D. Mastoid osteoma: report of two cases. Eur Ann Otorhinolaryngol Head Neck Dis 2011; 128: 266-8.

11. Arslan HH, Tasli H, Cebeci S, Gerek M. The management of the paranasal sinus osteomas. J Craniofac Surg 2017; 28: 7415.

12. Yamasoba T, Harada T, Okuno T, Nomura Y. Osteoma of the middle ear. Report of a case. Arch Otolaryngol Head Neck Surg 1990; 116: 1214-6.

13. Secer HI, Gonul E, Izci Y. Surgical management and outcome of large orbitocranial osteomas. J Neurosurg 2008; 109: 4727.

14. Woldenberg Y, Nash M, Bodner L. Peripheral osteoma of the maxillofacial region. Diagnosis and management: a study of 14 cases. Med Oral Patol Oral Cir Bucal 2005; 10 Suppl 2: E139-42.

15. Ramirez-Camacho R, Vicente J, Ramon y Cajal S. Imaging quiz case 2. Osteoma of the mastoid antrum and cholesteatoma. Arch Otolaryngol Head Neck Surg 1999; 125: 349-52.

16. Dominguez Perez AD, Rodriguez Romero R, Dominguez Duran E, Riquelme Montano P, Alcantara Bernal R, Monreal Rodriguez C. The mastoid osteoma, an incidental feature? Acta Otorrinolaringol Esp 2011; 62: 140-3.

17. Singh RK, Goyal A, Kumar A, Kataria G, Kesarwani A. Mastoid osteoma of temporal bone - a rare case report. J Clin Diagn Res 2017; 11: MD01-2.

18. Park SJ, Kim YH. A case of giant osteoma developed from the 
mastoid cortical bone. Korean J Audiol 2012; 16: 95-8.

19. Sakthivel P, Yogal R, Sikka K, Thakar A, Rajeshwari M. Mastoid osteoma - is "Trauma" a possible etiologic factor. JNMA J Nepal Med Assoc 2017; 56: 367-70.

20. Guerin N, Chauveau E, Julien M, Dumont JM, Merignargues G. Osteoma of the mastoid: apropos of 2 cases. Rev Laryngol Otol Rhinol (Bord) 1996; 117: 127-32.

21. Abdel Tawab HM, Kumar VR, Tabook SM. Osteoma presenting as a painless solitary mastoid swelling. Case Rep Otolaryngol 2015; 2015: 590783.

22. Ragupathy K, Priyadharsini I, Sanjay P, Yuvaraj V, Balaji TS. Peripheral osteoma of the body of mandible: a case report. J Maxillofac Oral Surg 2015; 14: 1004-8.

23. Halawi AM, Maley JE, Robinson RA, Swenson C, Graham
SM. Craniofacial osteoma: clinical presentation and patterns of growth. Am J Rhinol Allergy 2013; 27: 128-33.

24. Van Dellen JR. A mastoid osteoma causing intracranial complications. A case report. S Afr Med J 1977; 51: 597-8.

25. Sayan NB, Uçok C, Karasu HA, Günhan O. Peripheral osteoma of the oral and maxillofacial region: a study of 35 new cases. J Oral Maxillofac Surg 2002; 60: 1299-301.

26. McCarthy EF. Fibro-osseous lesions of the maxillofacial bones. Head Neck Pathol 2013; 7: 5-10.

27. Probst LE, Shankar L, Fox R. Osteoma of the mastoid bone. J Otolaryngol 1991; 20: 228-30.

28. Starch-Jensen T. Peripheral solitary osteoma of the zygomatic arch: a case report and literature review. Open Dent J 2017; 11: 120-5. 